\section{Tropical Journal of Pathology and Microbiology}

\title{
Association of serum prostate-specific antigen with Complete Blood Counts in patients with prostatic cancer
}

\author{
Rashmi G S Basavaraj ${ }^{1}$, Ravikumar Malladad ${ }^{2 *}$ \\ DOI: https://doi.org/10.17511/jopm.2021.i04.02 \\ ${ }^{1}$ Rashmi G S Basavaraj, Consultant Pathologist, Malladad Rudramma Memorial Hospital, Haveri, Karnataka, India. \\ 2* Ravikumar Malladad, Consultant Physician, Malladad Rudramma Memorial Hospital, Haveri, Karnataka, India.
}

\begin{abstract}
Background: Prostate cancer is the second most common cancer and one of the most leading causes of death in men worldwide. The prostate-specific antigen (PSA) as a screening method showed that there has been a slight decrease in prostate cancer mortality. Effective biomarkers in screening and diagnosis would be beneficial for avoiding unnecessary operations. The predictive and prognostic value of complete blood count $(C B C)$ has been manifested by recent studies. We aimed to determine the association of serum PSA with Complete blood counts in patients with prostate cancer. Method: The present study included 100 subjects, 50 patients diagnosed with new prostate cancer and 50 patients with prostate cancer. All the was undertaken in the central diagnostic laboratory at VIMS and RC. Blood samples were collected from all the subjects after taken permission from the institutional ethics committee and consent form. The haemoglobin, RBCs, MCV, MCHC, RDW will be analysed by using laboratory standard methods (Beckman coulter LH-780) and The serum PSA levels are estimated by commercially available kits based on enzyme-linked immunosorbent assay (ELISA). Results: In the present study found significantly elevated levels of a prostate specific antigen in both groups of prostatic cancer patients. The reduced levels of hemoglobin, red blood cells, platelets, neutrophils were observed in prostatic cancer patients when compared to newly diagnosed prostate cancer patients. The PSA levels were negatively correlated with total blood counts. Conclusion: This study suggests that the elevated levels of prostate specific antigen were useful for diagnosis and prognosis of prostatic cancers, along with the monitoring of complete blood count may be useful for the treatment of patients with prostatic cancers.
\end{abstract}

Keywords: Prostate Cancer, PSA, Hemoglobin and RBCs

Corresponding Author

Ravikumar Malladad, Consultant Physician, Malladad Rudramma Memorial Hospital, Haveri, Karnataka, India.

Email: rashmimallada@gmail.com
How to Cite this Article

Rashmi G S Basavaraj, Ravikumar Malladad. Association of serum prostate-specific antigen with Complete Blood Counts in patients with prostatic cancer. Trop J Pathol Microbiol. 2021;7(3):162-169. Available From

https://pathology.medresearch.in/index.php/jopm/ar ticle/view/561
To Browse

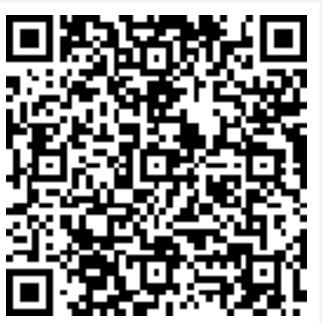

Manuscript Received 2021-06-05

Conflict of Interest No
Review Round 1 2021-06-27

Funding $\mathrm{Nil}$

Review Round 2
2021-07-15
Ethical Approval
Yes

Review Round 2

Yes

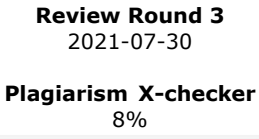

Accepted 2021-08-20

Note

(C) 2021 by Rashmi G S Basavaraj, Ravikumar Malladad and Published by Siddharth Health Research and Social Welfare Society This is an Open Access article licensed under a Creative Commons Attribution 4.0 International License https://creativecommons.org/licenses/by/4.0/ unported [CC BY 4.0]. 


\section{Introduction}

Prostate cancer (PCa) is also one of the most common cancers in worldwide and diagnostic tools of PC by prostate specific antigen (PSA). The increasing incidence of $\mathrm{PCa}$ related mortality rate has been reduced [1-2]. It has been differed in tumor markers and contributes to genetic factors, metabolic disturbances that happen in the prostatic tissue, benign prostatic hyperplasia and prostatic cancer [3-5]. The incidence of prostate cancer varies remarkably in different countries and regions, which increased significantly during the past few decades due to diverse approaches to diagnosing PCa. Despite different treatment methods including radical prostatectomy, hormone deprivation therapy, radiation therapy and chemotherapy were applied, most tumours relapse in 2 years to the castrationresistant state and the prognosis of $\mathrm{PCa}$ remains disappointing [6-7]. Given this, it is of interest for clinicians to stratify the high-risk PCa patients who are prone to tumour recurrence and poor prognosis so that clinicians could further identify optimal treatment strategies [8]. The changes in systemic inflammatory response can be reflected by the measurement of various blood-based parameters. A variety of blood-based indexes including C-reactive protein (CRP), modified Glasgow Prognostic Score (mGPS), platelets count and neutrophil-tolymphocyte ratio (NLR) has been extensively explored to predict the prognosis of cancer patients. A large number of studies have reported that elevation of NLR was associated with poor clinical outcomes in various malignant tumours [9]. In recent years, several studies have reported that an elevation in NLR correlated with biological tumor recurrence and poor prognosis in patients with $\mathrm{PCa}$. The prostate specific antigen and prostate acid phosphatase were used for the diagnosis of prostatic cancer [10]. PSA is a glycoprotein that contains 237 amino acids produced by the lamina of the prostate gland and circulated in the bloodstream exist 2 major forms [11]. The PSA levels are useful for prostate cancer detection and predict prognosis in men with prostate cancer undergoing therapy. The prevalence of symptomatic prostatitis was $9 \%$ in men above the age of 40 years, although the prevalence of asymptomatic prostatitis was unknown [12]. In addition, prostatic lesions called proliferative inflammatory atrophy and prostatic intraepithelial neoplasia are considered precursors of prostate cancer [13-14]. This term includes focal atrophic lesions as well as chronic inflammation.
Inflammatory cells release several oxidative materials which may lead to genomic and cellular damage [15]. The predictive and prognostic value of complete blood count ( $C B C$ ) has been manifested by recent studies. It has been known that there is an association between inflammation and cancer and the use of $C B C$ is the subject of research because of its capability to show an inflammatory process in the early stages of diseases. The results of $\mathrm{CBC}$ differ in cancer patients and give us some clues about the prognosis of the disease [16]. This suggests that routine $\mathrm{CBC}$ may be used for different purposes such as cancer screening, diagnoses or follow-ups in the future. We aimed to evaluate the serum prostate specific antigen with complete blood counts in patients among two groups of prostatic cancer.

\section{Materials and Methods}

Settings: This study was conducted in the Department of Pathology at the Institute of Medical Science, Karnataka.

Duration and Type of The study: This is a crosssectional observational study conducted from June 2014- Aug 2016.

Sampling Methods: A total of 100 subjects were included in the present study 50 patients diagnosed with Prostate cancer and 50 patients with prostatic cancer on treatment.

\section{Sample Size: 100 Cases}

Inclusion Criteria: Patients with prostatic cancer and age more than 30 years were included in the present study.

Exclusion Criteria: Patients with acute indications for surgical intervention such as: refractory hematuria, recurrent UTI, concomitant bladder stones, second renal insufficiency, Urinary Tract Infections, other types of cancers and inguinal hernia were excluded from this study.

Data collection and Procedures: From all subjects, after overnight fasting (12hrs), $6 \mathrm{~mL}$ of venous blood was collected and $2 \mathrm{~mL}$ transferred into EDTA tube, remaining $3 \mathrm{~mL}$ transferred into the plain tube. The collected samples were separated by centrifugation at $4000 \mathrm{rpm}$ for $15 \mathrm{~min}$ and stored until biochemical analysis was done. The serum prostate-specific antigen was analysed by using Enzyme-Linked Immunosorbent Assay "ELISA" and the complete blood count were analysed by using standard laboratory methods (Sysmax auto analyzer 
Ethical considerations and Permission: All the subjects were recruited in the study after obtaining their informed consent after obtaining of ethical clearance from the institute.

Statistical Analysis: The normal distribution of data was checked by using the Kolmogorov Smirnov test. All the characters are descriptively summarized. The mean and standard deviation of the arithmetic mean were used. Variations in the serum Prostate Specific Antigen (PSA was analysed by using Student's T-Tests ( 2 Tailed). The correlation between the PSA, CBC was done by using Pearson Correlation analysis. The Data has been compiled in Microsoft Excel spreadsheets and analyzed using SPSS for windows version 16.0. A pvalue $<0.05$ was considered statistically significant.

\section{Results}

Table - 1 shows the mean values and SD of patient's charactertic's and various parameters studied inprostate cancer and healthy controls. Significant difference was observed hemoglobin $\left(9.15 \pm 0.72,12.83 \pm 0.31 \mathrm{P}-0.0001^{*}\right)$, Red blood cells $\left(2.51 \pm 1.92,4.28 \pm 0.14, \mathrm{P}-0.002^{*}\right)$, WBCs $\left(2011.54 \pm 30.66,6045.15 \pm 25.24, \mathrm{P}-0.0001^{*}\right)$, Platelets (1.02 $\left.\pm 0.29,4.38 \pm 17.36, \mathrm{P}-0.0001^{*}\right)$, Neutrophils $(35.62 \pm 6.49,5.25 \pm 35.07, \quad P-$ $\left.0.004^{*}\right)$, PSA $(9.68 \pm 2.11,5.13 \pm 1.56, \mathrm{P}$ $0.001^{*}$ ) in the groups of prostatic cancer patients. Significantly higher levels of serum prostate specific antigen and decreased levels were observed in patients with prostate cancer on treatment when compared with newly diagnosed prostate cancer patients $(p<0.001)$.

\begin{tabular}{|l|l|l|l|}
\hline Parameter & \multicolumn{1}{|c|}{$\begin{array}{c}\text { Newly Prostate } \\
\text { Cancer }\end{array}$} & \multicolumn{1}{|c|}{$\begin{array}{c}\text { Prostate Cancer on } \\
\text { Treatment }\end{array}$} & $\begin{array}{c}\text { P } \\
\text { value }\end{array}$ \\
\hline $\begin{array}{l}\text { Age (Years) } \\
\text { gloemo- }\end{array}$ & $12.63 \pm 8.37$ & $51.51 \pm 7.19$ & 0.935 \\
\hline RBCs & $4.28 \pm 0.14$ & $9.15 \pm 0.72$ & 0.686 \\
\hline Platelets & $4.38 \pm 17.36$ & $1.02 \pm 0.29$ & 0.513 \\
\hline WBCs & $6045.15 \pm 25.24$ & $2011.54 \pm 30.66$ & $0.001 *$ \\
\hline Neutrophils & $5.25 \pm 35.07$ & $35.62 \pm 6.49$ & $0.012 *$ \\
\hline PSA (ng/ML) & $5.13 \pm 1.56$ & $9.68 \pm 2.11$ & $0.001 *$ \\
\hline
\end{tabular}

Table-1. Comparison of biochemical parameters in patients with two groups of Prostate Cancer

Table - 2 shows the positive correlation of SerumPSA and complete blood count in both the groups of prostatic cancer patients.
The serum prostate specific antigens were negatively correlated with complete blood count in patients with prostatic cancer.

Table -2. Pearson Correlation in between serum PSA/PAP with Liver Function Tests

\begin{tabular}{|l|l|l|l|}
\hline Parameter & & \multicolumn{1}{|c|}{ r value } & \multicolumn{1}{c|}{ P-value } \\
\hline \multirow{4}{*}{ PSA } & Haemoglobin & -0.040 & $0.0001^{* *}$ \\
\cline { 2 - 4 } & RBCs & -0.030 & $0.0001^{* *}$ \\
\cline { 2 - 4 } & Platelets & -0.277 & $0.0001^{* *}$ \\
\cline { 2 - 4 } & WBCs & -0.236 & $0.0001^{* *}$ \\
\cline { 2 - 4 } & Neutrophils & -0.394 & $0.0001^{* *}$ \\
\hline
\end{tabular}

\section{Discussion}

Prostate-specific antigen synthesized from the epithelium of the prostate gland and secreted into the seminal fluid to maintain liquefaction of seminal fluid [17]. In circulation this will present in two major forms, complexed form bound with alpha 1antitrypsin and another form free form. The normal serum levels of total PSA are less than $4 \mathrm{ng} / \mathrm{L}$ [18]. The measurement of serum PSA levels is useful for the early detection and progression of prostatic cancer. The present study also found significantly elevated levels of serum prostate specific antigen levels were observed in both the groups of prostate cancer patients [19]. Previous studies were done a systemic review on PSA screening, the elevated levels are useful for early detection and progression of prostate cancer when compared with the controls [20]. Based on evidence that early androgen deprivation therapy improves outcomes in certain clinical settings, many men with non-metastatic prostate cancer are treated with gonadotropinreleasing hormone agonists. Early primary androgen deprivation therapy improves survival for men with locally advanced prostate cancer. Adjuvant androgen deprivation therapy improves survival for men with locally advanced prostate cancer treated with radiation therapy, Men are with a strong family history of prostate cancer and PSA Screening can reduce the mortality from prostate cancer [21]. Men with metastatic prostate cancer and disease progression despite androgen deprivation therapy have a poor prognosis. In two recent randomized controlled trials for example, the median survival was only 16 to 18 months for men with progressive castrate metastatic prostate cancer. Recent changes in patterns of diagnosis and treatment have dramatically increased the number of men receiving gonadotropin-releasing hormone agonists for nonmetastatic prostate cancer [22]. 
Although most of these men will eventually experience rising PSA despite castrate levels of testosterone, little is known about the natural history of men with androgen-independent prostate cancer and no radiographic evidence of metastases [23]. To the best of our knowledge, this is the first analysis to prospectively evaluate the natural history of non-metastatic prostate cancer and rising PSA despite androgen deprivation therapy [24]. Notable features of the study design include confirmation of a castrate testosterone level at study entry, documentation of PSA progression with three serial rises, and radiographic screening to exclude men with bone metastases at study entry [25]. In addition, bone scans were obtained every 4 months to minimize PSA bias in defining the primary study outcome of time to first bone metastases.

Elevation in serum PSA levels after surgery or radiation therapy for early-stage prostate cancer typically predates clinically or radiographically detectable metastatic disease by several years, without additional treatment. In a retrospective series of 315 men with a rising serum PSA after radical prostatectomy for example, the median time to first bone metastasis was 8 years from the time of PSA elevation [26-28]. Three years following initial postoperative PSA elevation, only $27 \%$ of patients had radiographically detectable metastases. The results of our study suggest that rates of disease progression remain low for men with "PSA only" prostate cancer, even after androgen deprivation therapy. Prostate adenocarcinoma proliferation is highly dependent on circulating sex steroids, specifically testosterone and dihydrotestosterone, and the binding of these hormones to receptors on prostate cancer cells.

Changes in sex steroid production, particularly decreased androgens and/or increased estrogens, can inhibit the growth and development of welldifferentiated prostate cancers but may have little influence or even an undesirable effect on poorly differentiated prostate tumors [29-30]. This phenomenon has been demonstrated with finasteride, which decreases the conversion of testosterone to dihydrotestosterone by inhibition of the 5-alpha reductase enzyme. In the Prostate Cancer Prevention Trial, finasteride was found to significantly prevent or delay prostate cancer by almost $25 \%$ overall, however, the risk for having high-grade disease, specifically Gleason grade 7 to 10 tumors, was significantly increased [31].
We also analysed complete blood count in both the groups of study subjects found significantly decreased levels in patients with prostatic cancer patients with on treatment when compared to newly diagnosed prostatic patients. Similarly other some of the few studies to date analyzed systemic inflammation as a function of the black race, particularly after treatment with radical prostatectomy (RP), included 336 black patients undergoing RP with data on pre-operative $\mathrm{CBC}$, found that those who had lower Neutrophils count also had higher clinical and pathological Gleason scores, indicating a high tumour grade at RP20. This study suggests continuous monitoring of serum prostate specific antigen and complete blood count useful for diagnosis and progression of prostatic cancer patients. Against this backdrop of uncertainties, risks, and potential benefits, we have developed a guideline that accentuates the importance of involving men in the decision of whether to initiate and continue testing for prostate cancer. To engage in this decision, men must have a basic understanding of the importance of prostate cancer, the potential benefits of early detection, the strengths and limitations of PSA testing, and the risks of finding and treating screen-detected cancer. In the guideline statement, we have attempted to provide the core elements of information necessary for an informed decision. How men use this knowledge will depend heavily on the value they place on the various elements: Is the opportunity to potentially lower a man's probability of dying from cancer worth the risk of deleterious effects of treatment [32]. Does the realization that some men are treated unnecessarily outweigh the reassurance that comes from finding cancer at an early stage. Previous studies also reported that biopsy samples were required to be obtained from patients with decreased neutrophils accompanied by a high level of PSA and patients with neutropenia were at a higher risk for poorly differentiated prostate cancer. In our study, we also obtained similar findings which were consistent with those reported by Although the WBC and neutrophil counts were lower in patients with prostate cancer, they did not reach statistical significance. In addition, patients with $\mathrm{BPH}$ had a higher level of neutrophils. Recently, however, it has been largely reported that leukocytosis as well as neutrophil-to-lymphocyte ratio and multiplied neutrophils and lymphocytes may be a diagnostic and prognostic tumor biomarker. Several studies demonstrated that the neutrophil-to-lymphocyte ratio is a prognostic factor for colorectal and nonsmall cell cancer $\lceil 331$. 
Highly significant differences in the expression of genes related to immunobiology within the tumour microenvironment were identified between these two groups. This interpretation was supported by both disease association and pathway analyses. $\mathrm{CBC}$, especially the systemic inflammatory parameters, contain many clues reflecting how the human mechanism works [34]. They are very helpful in the diagnosis of many diseases in addition to the physical examination findings. Recent studies have shown that $\mathrm{CBC}$ findings might also be used in tumoral diseases. The relationship between inflammation and cancer has been already known for decades. It has been known that some cancers develop on the ground of chronic inflammation or some infectious agents are involved in cancer etiology. However, during cancer development, inflammatory mediators play an important role in creating a microenvironment that will allow the tumour to grow and spread. Further, many studies suggest that not only the inflammatory response in the tumoral tissue but also the systemic inflammatory response is associated with the tumor prognosis [35-36]. Similar to the inflammatory cells, platelets play a role in the development of cancer. Platelets also contribute to the formation of angiogenesis by stimulating vascular and endothelial growth factors, in turn supporting cancer development [37]. Moreover, platelets play an active role in the metastatic process by facilitating the adhesion of cells to the vessels and the thrombocytosis is also associated with advanced or metastatic cancers and is regarded as a negative predictive marker for many cancers such as endometrial, cervical, ovarian, gastric, and esophageal carcinoma, and breast cancer.

\section{Conclusion}

This study suggesting that the serum Prostatic Specific Antigen (PSA) levels sensitive parameters for early detection of prostatic cancer and also for these patients frequent measurements of complete blood count useful for early detection of further complications.

\section{What new this study adds to existing knowledge}

In prostate cancers by using prostate specific antigens and prostate phosphatase were used for diagnosis and progression of prostatic cancers. But these prostate cancers leads to further complications on bone and liver, some blood-related
Metastasis, for continuous monitoring of complete blood count as well as prostate-specific antigen and prostate acid phosphatase.

\section{Authors Contribution}

Dr. Rashmi GS Basavaraj, Data collection, Literature review, Manuscript preparation, Manuscript editing, Final approval. Dr. Ravikumar Malladad, Patients Selection, Collection of Samples, Data Analysis and Statistical analysis.

\section{Reference}

01. Christudoss $P$, Selvakumar R, Fleming JJ, Gopalakrishnan G. Zinc status of patients with benign prostatic hyperplasia and prostate carcinoma. Indian J Urol. 2011 Jan;27(1)14-8. doi: 10.4103/0970-1591.78405 [Crossref][PubMed] [Google Scholar]

02. Sarwar S, Adil M A M, Nyamath P, Ishaq M. Biomarkers of prostatic cancer: an attempt to categorize patients into prostatic carcinoma, benign prostatic hyperplasia, or prostatitis based on serum prostate specific antigen, prostatic acid phosphatase, calcium, and phosphorus. Prostate Cancer. 2017. [Crossref][PubMed][Google Scholar]

03. Vickers AJ. Prostate Cancer Screening- Time to Question How to Optimize the Ratio of Benefits and Harms. Ann Intern Med. 2017 Oct 3;167(7)509510. doi: 10.7326/M17-2012 [Crossref][PubMed] [Google Scholar]

04. Lin K, Lipsitz R, Miller T, Janakiraman S. US Preventive Services Task Force, Benefits and harms of prostate-specific antigen screening for prostate cancer- an evidence update for the US Preventive Services Task Force. Ann Intern Med. 2008; 149(3)192-9. doi: 10.7326/0003-4819-149-3-2008 08050-00009 [Crossref][PubMed][Google Scholar]

05. Catalona WJ, Partin AW, Slawin KM, Brawer MK, Flanigan RC, Patel $A$, et al. Use of the percentage of free prostate-specific antigen to enhance differentiation of prostate cancer from benign prostatic disease- a prospective multicenter clinical trial. JAMA. 1998 May 20;279(19)1542-7. doi: 10.1001/jama.279.19.1542 [Crossref][PubMed] [Google Scholar]

06. McNeal JE. Regional morphology and pathology of the prostate. Am J Clin Pathol. 1968 Mar;49(3)347-57. doi: 10.1093/ajcp/49.3.347 [Crossref][PubMed][Google Scholar] 
07. Ercole CJ, Lange $\mathrm{PH}$, Mathisen M, Chiou RK, Reddy PK, Vessella RL. Prostatic specific antigen and prostatic acid phosphatase in the monitoring and staging of patients with prostatic cancer. J Urol. 1987 Nov;138(5)1181-4. doi: 10.1016/s00225347(17)43543-9 [Crossref][PubMed][Google Scholar]

08. Mittal, Rama Devi, et al. "Total PSA and free PSA in patients with severe liver dysfunction". Indian Journal of Urology. 19;2(2003)117. [Crossref] [PubMed][Google Scholar]

Bañez LL, Loftis RM, Freedland SJ, Presti JC Jr, Aronson WJ, Amling $\mathrm{CL}$, et al. The influence ofhepatic function on prostate cancer outcomes after radical prostatectomy. Prostate Cancer Prostatic Dis. 2010 Jun;13(2)173-7. doi: 10.1038/pcan.2010.3 [Crossref][PubMed][Google Scholar]

10. Lucia MS, Epstein JI, Goodman PJ, Darke AK, Reuter VE, Civantos $F$, et al. Finasteride and highgrade prostate cancer in the Prostate Cancer Prevention Trial. J Natl Cancer Inst. 2007 Sep 19;99(18)1375-83. doi: 10.1093/jnci/djm117 [Crossref][PubMed][Google Scholar]

11. Han PK, Kobrin S, Breen N, Joseph DA, Li J, Frosch DL, Klabunde CN. National evidence on the use of shared decision making in prostate-specific antigen screening. Ann Fam Med. 2013 JulAug;11(4)306-14. doi: 10.1370/afm.1539 [Crossref][PubMed][Google Scholar]

12. Ilic D, Djulbegovic $M$, Jung JH, Hwang EC, Zhou $Q$, Cleves $A$, et al. Prostate cancer screening with prostate-specific antigen (PSA) test- a systematic review and meta-analysis. BMJ. 2018 Sep 5;362;k3519. doi: 10.1136/bmj.k3519 [Crossref] [PubMed][Google Scholar]

13. US Preventive Services Task Force, Grossman DC, Curry SJ, Owens DK, Bibbins-Domingo $\mathrm{K}$, Caughey $A B$, et al. Screening for Prostate CancerUS Preventive Services Task Force Recommendation Statement. JAMA. 2018 May 8;319(18)1901-1913. doi: 10.1001/jama.2018.3710 [Crossref][PubMed] [Google Scholar]

14. Fenton JJ, Weyrich MS, Durbin S, Liu Y, Bang $H$, Melnikow J. Prostate-Specific Antigen-Based Screening for Prostate Cancer- Evidence Report and Systematic Review for the US Preventive Services Task Force. JAMA. 2018 May 8;319(18)1914-1931. doi: 10.1001/jama.2018.3712 [Crossref][PubMed] [Google Scholar]
15. Sarwar $S$, Adil MA, Nyamath $P$, Ishaq $M$. Biomarkers of Prostatic Cancer: An Attempt to Categorize Patients into Prostatic Carcinoma, Benign Prostatic Hyperplasia, or Prostatitis Based on Serum Prostate Specific Antigen, Prostatic Acid Phosphatase, Calcium, and Phosphorus. Prostate Cancer. 2017;5687212. doi: 10.1155/2017/5687212 [Crossref][PubMed][Google Scholar]

16. Vihko $P$, Kontturi M, Korhonen LK. Purification of human prostatic acid phosphatase by affinity chromatography and isoelectric focusing. Part I- Clin Chem. 1978 Mar;24(3)466-70. [Crossref][PubMed] [Google Scholar]

17. Gunia S, Koch S, May M, Dietel M, Erbersdobler A. Expression of prostatic acid phosphatase (PSAP) in transurethral resection specimens of the prostate is predictive of histopathologic tumor stage in subsequent radical prostatectomies. Virchows Arch. 2009 May;454(5)573-9. doi: 10.1007/s00428-0090759-1 [Crossref][PubMed][Google Scholar]

18. Kirschenbaum A, Izadmehr S, Yao S, O'ConnorChapman KL, Huang A, Gregoriades EM, Yakar S, Levine AC. Prostatic Acid Phosphatase Alters the RANKL/OPG System and Induces Osteoblastic Prostate Cancer Bone Metastases. Endocrinology. 2016 Dec;157(12)4526-4533. doi: 10.1210/en.2016-1606 [Crossref][PubMed][Google Scholar]

19. Larson SR, Chin J, Zhang X, Brown LG, Coleman IM, Lakely $B$, et al. Prostate cancer derived prostatic acid phosphatase promotes an osteoblastic response in the bone microenvironment. Clin Exp Metastasis. 2014 Feb;31(2)247-56. doi: 10.1007/s10585-0139625-2 [Crossref][PubMed][Google Scholar]

20. Christudoss $P$, Selvakumar R, Fleming JJ, Gopalakrishnan G. Zinc status of patients with benign prostatic hyperplasia and prostate carcinoma. Indian J Urol. 2011 Jan;27(1)14-8. doi: 10.4103/0970-1591.78405 [Crossref][PubMed] [Google Scholar]

21. Sarwar Shahana, Adil M A M, Nyamath $P$, Ishaq M. "Biomarkers of prostatic cancer: an attempt to categorize patients into prostatic carcinoma, benign prostatic hyperplasia, or prostatitis based on serum prostate specific antigen, prostatic acid phosphatase, calcium, and phosphorus". Prostate Cancer. 2017. [Crossref][PubMed][Google Scholar] 
22. Vickers AJ. Prostate Cancer Screening- Time to Question How to Optimize the Ratio of Benefits and Harms. Ann Intern Med. 2017 Oct 3;167(7)509510. doi: 10.7326/M17-2012 [Crossref][PubMed] [Google Scholar]

23. Lin K, Lipsitz R, Miller T, Janakiraman S. US Preventive Services Task Force, Benefits and harms of prostate-specific antigen screening for prostate cancer- an evidence update for the US Preventive Services Task Force. Ann Intern Med. 2008 Aug 5;149(3)192-9. doi: 10.7326/0003-4819-149-3200808050-00009

[Crossref][PubMed][Google

Scholar]

24. Catalona WJ, Partin AW, Slawin KM, Brawer MK, Flanigan RC, Patel $A$, et al. Use of the percentage of free prostate-specific antigen to enhance differentiation of prostate cancer from benign prostatic disease- a prospective multicenter clinical trial. JAMA. 1998 May 20;279(19)1542-7. doi: 10.1001/jama.279.19.1542 [Crossref][PubMed] [Google Scholar]

25. McNeal JE. Regional morphology and pathology of the prostate. Am J Clin Pathol. 1968 Mar;49(3)347-57. doi: 10.1093/ajcp/49.3.347 [Crossref][PubMed][Google Scholar]

26. Ercole $\mathrm{CJ}$, Lange $\mathrm{PH}$, Mathisen $\mathrm{M}$, Chiou $\mathrm{RK}$, Reddy PK, Vessella RL. Prostatic specific antigen and prostatic acid phosphatase in the monitoring and staging of patients with prostatic cancer. J Urol. 1987 Nov;138(5)1181-4. doi: 10.1016/s00225347(17)43543-9 [Crossref][PubMed][Google Scholar]

27. Mittal R D, Singh M K, Selvaraju C, Choudhuri G. Total PSA and free PSA in patients with severe liver dysfunction. Indian Journal of Urology. 19;2(2003)117. [Crossref][PubMed][Google Scholar]

28. Bañez LL, Loftis RM, Freedland SJ, Presti JC Jr, Aronson WJ, Amling $\mathrm{CL}$, et al. The influence of hepatic function on prostate cancer outcomes after radical prostatectomy. Prostate Cancer Prostatic Dis. 2010 Jun;13(2)173-7. doi: 10.1038/pcan.2010.3 [Crossref][PubMed][Google Scholar]

29. Lucia MS, Epstein JI, Goodman PJ, Darke AK, Reuter VE, Civantos $F$, et al. Finasteride and highgrade prostate cancer in the Prostate Cancer Prevention Trial. J Natl Cancer Inst. 2007 Sep 19;99(18)1375-83. doi: 10.1093/jnci/djm117 [Crossref][PubMed][Google Scholar]
30. Han PK, Kobrin S, Breen N, Joseph DA, Li J, Frosch DL, et al. National evidence on the use of shared decision making in prostate-specific antigen screening. Ann Fam Med. 2013 Jul-Aug;11(4)30614. doi: 10.1370/afm.1539 [Crossref][PubMed] [Google Scholar]

31. Ilic D, Djulbegovic M, Jung JH, Hwang EC, Zhou $Q$, Cleves $A$, et al. Prostate cancer screening with prostate-specific antigen (PSA) test- a systematic review and meta-analysis. BMJ. 2018 Sep 5;362;k3519. doi: 10.1136/bmj.k3519 [Crossref] [PubMed][Google Scholar]

32. US Preventive Services Task Force, Grossman DC, Curry SJ, Owens DK, Bibbins-Domingo $\mathrm{K}$, Caughey $A B$, et al. Screening for Prostate CancerUS Preventive Services Task Force Recommendation Statement. JAMA. 2018 May 8;319(18)1901-1913. doi: 10.1001/jama.2018.3710 [Crossref][PubMed] [Google Scholar]

33. Fenton JJ, Weyrich MS, Durbin S, Liu $Y$, Bang $H$, Melnikow J. Prostate-Specific Antigen-Based Screening for Prostate Cancer- Evidence Report and Systematic Review for the US Preventive Services Task Force. JAMA. 2018 May 8;319(18)1914-1931. doi: 10.1001/jama.2018.3712 [Crossref][PubMed] [Google Scholar]

34. Sarwar $S$, Adil MA, Nyamath $P$, Ishaq $M$. Biomarkers of Prostatic Cancer: An Attempt to Categorize Patients into Prostatic Carcinoma, Benign Prostatic Hyperplasia, or Prostatitis Based on Serum Prostate Specific Antigen, Prostatic Acid Phosphatase, Calcium, and Phosphorus. Prostate Cancer. 2017;5687212. doi:10.1155/2017/5687212 [Crossref][PubMed][Google Scholar]

35. Vihko $\mathrm{P}$, Kontturi M, Korhonen LK. Purification of human prostatic acid phosphatase by affinity chromatography and isoelectric focusing. Part I, Clin Chem. 1978 Mar;24(3)466-70. [Crossref][PubMed] [Google Scholar]

36. Johansen JS, Brasso $K$, Iversen $P$, Teisner $B$, Garnero P, Price PA, Christensen IJ. Changes of biochemical markers of bone turnover and YKL-40 following hormonal treatment for metastatic prostate cancer are related to survival. Clin Cancer Res. 2007 Jun 1;13(11)3244-9. doi: 10.1158/10780432.CCR-06-2616 [Crossref][PubMed][Google Scholar] 
37. Schröder FH, Tombal B, Miller K, Boccon-Gibod L, Shore ND, Crawford ED, et al. Changes in alkaline phosphatase levels in patients with prostate cancer receiving degarelix or leuprolide: results from a 12month, comparative, phase III study. BJU Int. 2010 Jul; 106(2)182-7. doi: $10.1111 / j .1464-$ 410X.2009.08981.x [Crossref][PubMed][Google Scholar] 